\section{Proactive strategic recruitment in research groups}

ccountability, improving quality The development and research process

Dr Jouni Kekäle, Human Resources Director at the
University of Eastern Finland, University of Eastern Finland, recruitment model to promote Successful recruitment is a significant aspect affecting with diversity within the research roup and academic freedom to crucial elements required that universities are searching model offers new insights and diversity to a research group by the means of the actual recruitments, cultivating strategic development with the potential to raise the

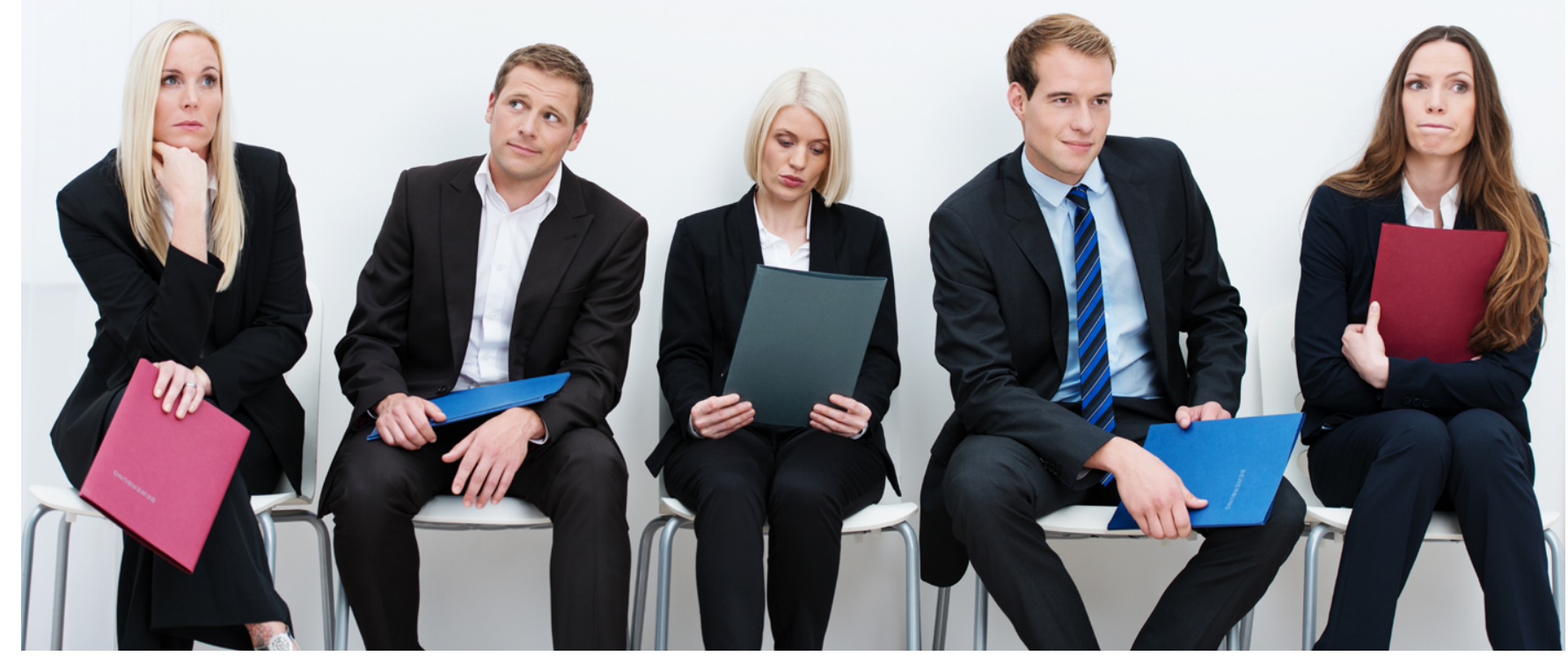

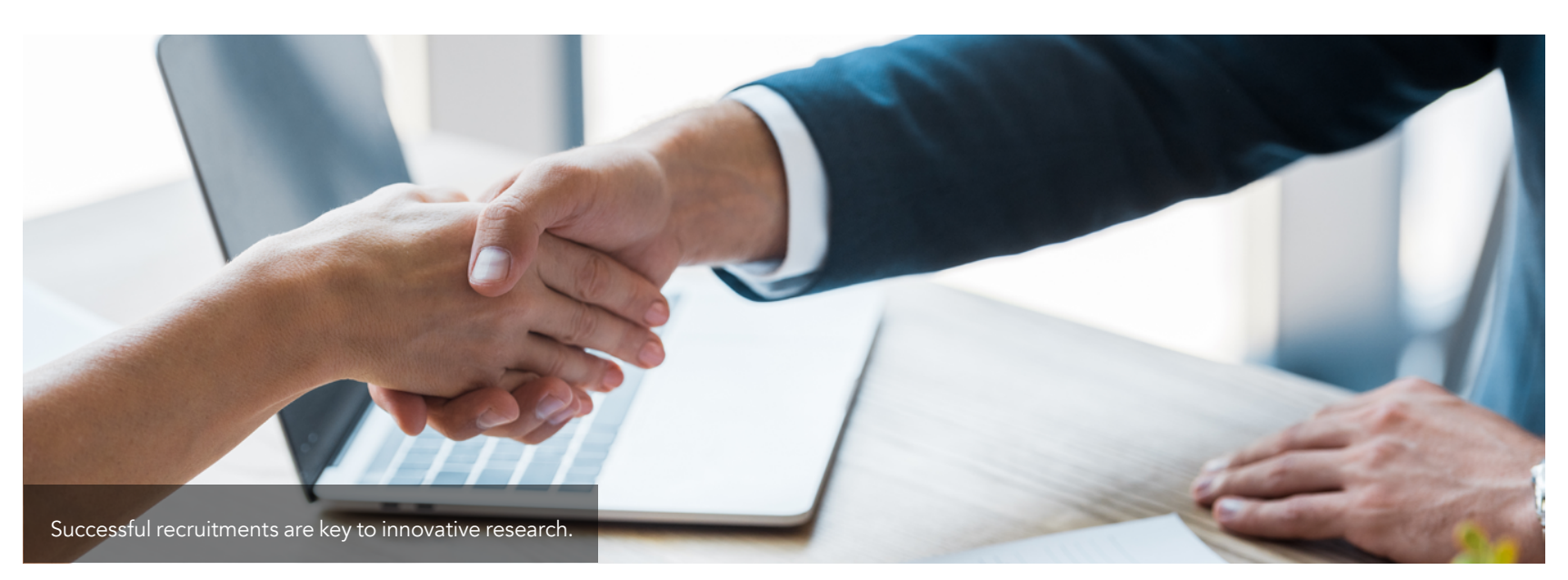

increase. Indeed, discussions with the leadership team at UEF revealed that they considered that novel research and breakthroughs in science inescapably require internal motivation, together hard work and in many cases, luck.

\section{THE PROACTIVE}

RECRUITMENT MODEL

The proactive model requires a research strengthening their to constantly while concurrently building a network of international researchers working in their area. Visits, collaboration and offering tenure track positions enable the group to develop relationships with likeminded researchers and discover their capabilities, thus expanding the pool of potential candidates before recruitment arises. This also overcomes the issue of candidates not knowing what it will be like to work at the new organisation, which was found to be the major barier for people changing jobs in a global Linkedin Survey.

Where traditional recruitment is viewed as an administrative procedure belonging to human resources management and recruitment is led by the academic leaders making the recruitment decisions and involves long term follow up, getting to know the candidate through their work. Deviating from the mainstream recrultment approach of waiting to see who responds to a vacancy announcement, the proactive model helps to find researchers with the necessary intrinsic motivation and aims that are analogous with the rest of the research group. The employer has the opportunity to judge the candidate's motivation and skills in real
life situations and assess if they might be movable when a suitable position arises. The proactive model also offers new insights and diversity to the resear group by the means of the actual recruitments, cultivating the group's to raise the research group to a new level of achievement.

DEVELOPING PROACTIV RECRUITMENT AT UEF Dr Kekäle reflects on the highly interactive was wide discussion of recruitment within the university. In addition to discussions within the leadership group
and the university's academic leaders,

two discussion rounds of the faculties took place, one led by Dr Kekale and the Jenni Varis. Overall, the faculties' staff Jennivaris. Overall, the faculies'staff con and validated the logic behind the model.

The university's leadership group have had a number of discussions on proactive recruitment and its operational goals and proposals in the context of international approaches to recruitment practice. Since 2016, developing recruitment has also featured in the annual leadership seminars with discussions involving the university's

Prior international networking is central to the model in order to enhance academic quality and broaden the recruitment pool.

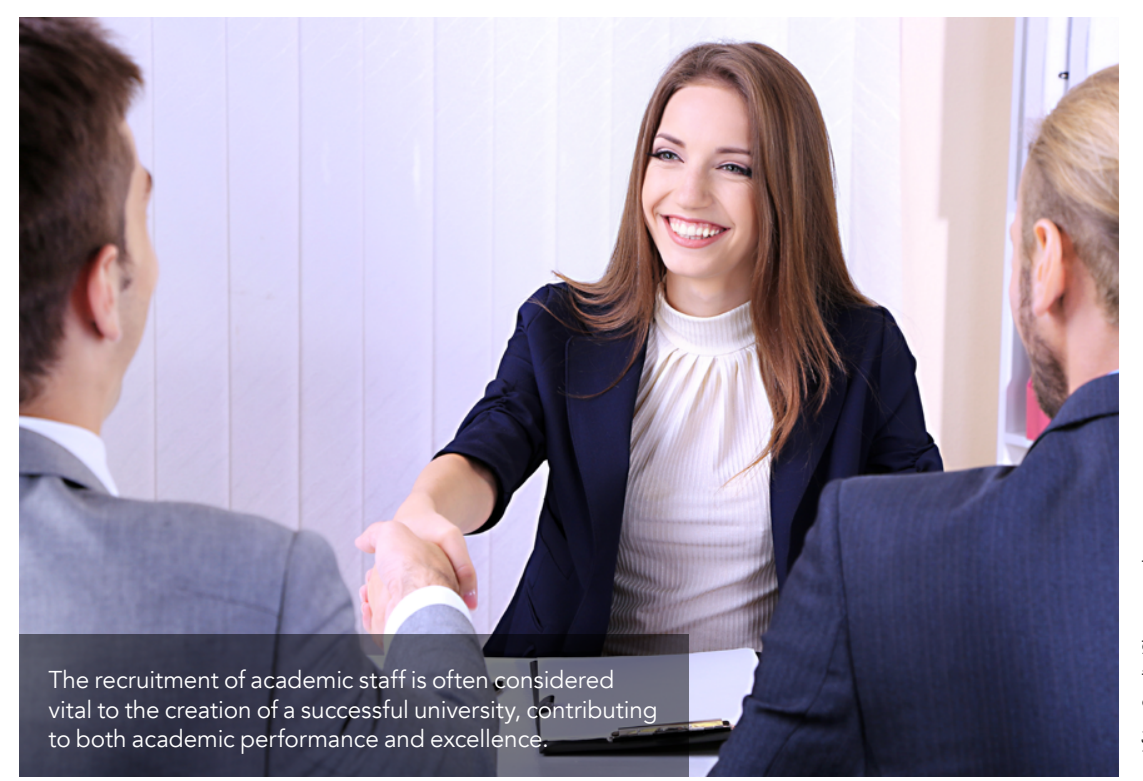
Rector of UEF, the other by Dr Kekale and 


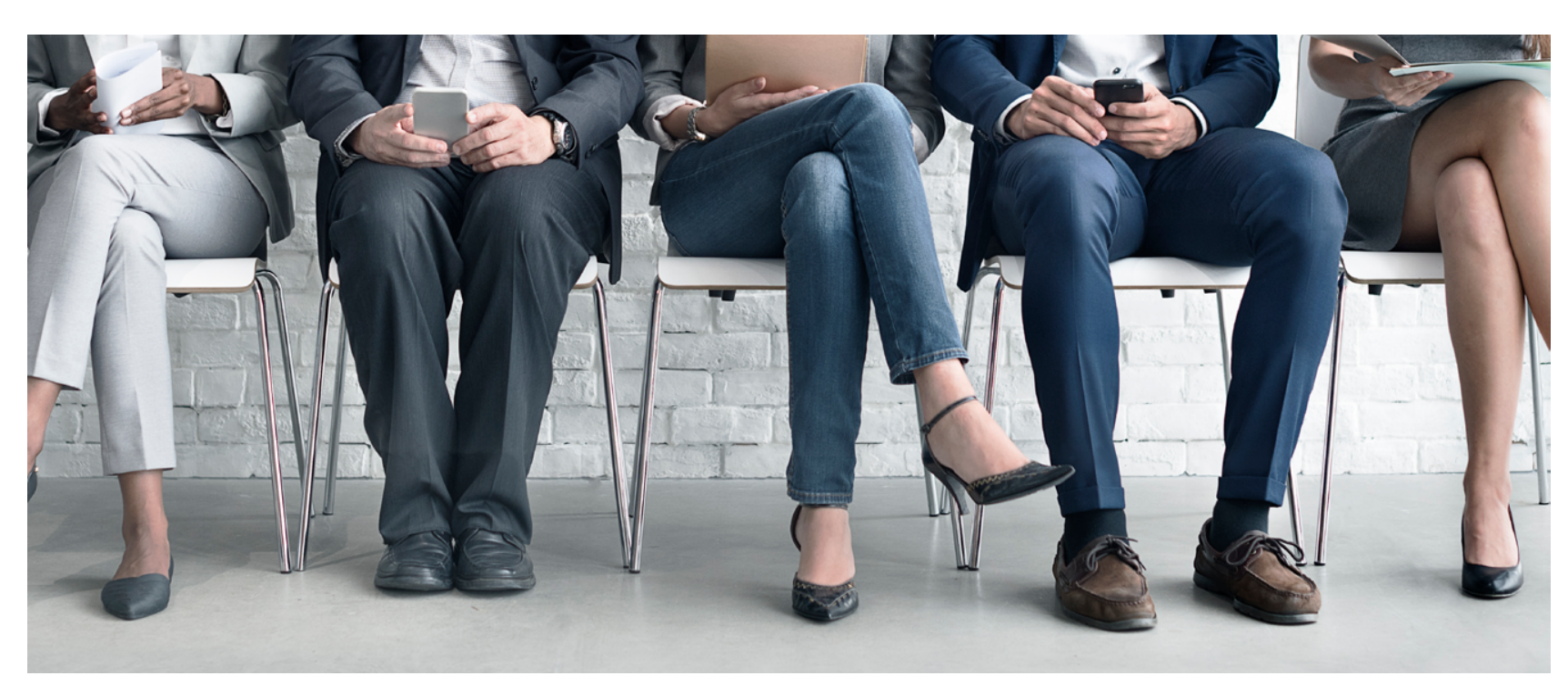

leaders and internal bodies dealing with research. Dr Kekäle explains that "in the discussions we have concluded that have not reached the global network of scholars to a sufficient degree, at least when considered against the university's strategy, stressing increasing internation recruitment. Recruitment has increasingly become proactive; a model of this has been formed through discussions in an iterative manner".

UEF identified five top-level international research areas in its strategy for

2015-2020. Dr Kekäle interviewed the professors in charge of these areas and together they discussed best practices and problems attached to recruitments. They also examined the proactive recruitment model which gained the support of all five research pesos, who acknowledged har they potential candidates.

\section{APPLYING PROACTIVE}

\section{RECRUITMENT}

Dr Kekäle draws attention to how the proactive model can be integrated into normal networking between researchers and requires little additional effort and investment from researchers and their universities. Researchers who are active in international networks naturally view these research networks as channels wha the posibility among participants in the long term.

Proactive recruitment is more straightforward for research groups that have already established strong reputations, as this makes them attractiv environment Research grion and work international contacts, which wo dynamic enough, may find it difficul to get started but they can still enhance their standing by developing a more proactive approach in the long term.

Successful recruitment is a significant feature affecting academic outcomes.

\section{THE RESPONSIBLE UNIVERSITY} Dr Kekäle defines a responsible university as "an institution that teaching, responds to the needs of society through basic tasks and aims t solving certain global problems of humankind while venerating the fundamental freedom of science". are crucial to achieving these goals. Furthermore, the development projects at UEF demonstrate how a university

Novel research and breakthroughs in science inescapably require internal motivation, together with hard work.

intrinsic motivation together with diversity within the research group and required to promote the in universities are searching for

\section{HUMAN RESOURCES}

\section{DEVELOPMENT}

Proactive recruitment forms part of the human resource development being carried out at UEF by Dr Kekale and his collaborators. The objectives of the development projects were to establish good practices, explore UEF and o cul leadership issues with UEF and to cultivate the development of these human resources $(H R)$ areas enabling UEF to meet its strategic plans The fundamental concepts that came out of these projects were the proactive recritment a d a thin

can nurture strategic aims and move world around us transforms. Proactive viewpoints of the various participants Dr Kekäle's research has shown that He goes on to explain how researchers towards solving global problems, responsible in the process.

Dr Kekäle describes how working solutions have to change as the recruitment and human resource development are dynamic processes and the processes described above are ongoing. This journey involves an iterative learning process that would be impossible without the cooperation ofhuman resources management and act trust toward and requires resilience, trust and willingness to understand the berdits in orde to the synergies and bend academic outcomes.

\section{Behind the Research}

\section{Dr Jouni Kekäle}

: Jouni.kekale@uef.fi T: +358503065370 W: https://www.uef.fi/en/etusivu

W: https://www.researchgate.net/profile/Jouni_Kekaele

Research Objectives

Jouni Kekäle's main research interests include human disciplinary, and organisational cultures in academia, and changing operational environment in Higher Education.

\section{Detail}

University of Eastern Finland
P.O. Box 111, Yliopistokatu 2

80101 Joensuu

Finland

Bio

Sekäle is both an academic (Higher Education Studies) and a practitioner as a HR Director in academia. He has acted as HR Director in universities for 20 years. He has participated in numerous institutional, national and international development projects. His most recent book is The Responsible University by Palgrave MacMillan (published as Open Access book https://ink.springer.com book/10.1007\%2F978-3-030-25646-3), which he co-edited.

Funding

University of Eastern Finland

Collaborators

Jukka Mönkkönnen, UEF

Head of Human Resources Jenni Varis, UEF

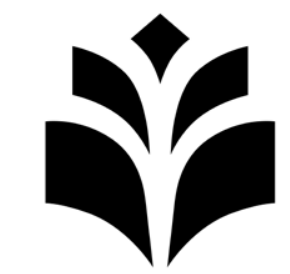

UNIVERSITY OF

EASTERN FINLAND
References

Kekäle, J. \& Varis, J. (2019). Responsible University: In Search of HR and Leadership Solutions. In. Sorensen, M.P. Geschwind, L., Kekäle, J \& Pinheiro, R. (Eds.) The Responsible University: Exploring the Nordic Context and Beyond. Palgrave Macmilian. Available at: https:///doi.org/10.1007/97894-017-9553-1_535-1 [Accessed 2nd January 2020]

Kekäle J. (2018). Human Resource Management, Higher Education. In: Teixeira P., Shin J. (eds) Encyclopedia of Springer Dordrecht Available at: https///doiorg/10 1007/97894-017-9553-1 535-1 [Accessed 2nd January 2020]

Kekäle, J. (2017). Proactive strategic recruitment in research groups, Tertiary Education and Management, 24(2), 144-153

Kekäle, J. (2015). A human resources model supporting academic excellence, Tertiary Education and Management, 21(2), 160-171

Kekäle, J. \& Pirttilä, I. (2006). Participatory action research as a method for developing leadership and quality. International Journal of Leadership in Education. (d) doi:10.1080/13603120600741359

\section{Personal Response}

What advice would you offer an institution that is considering using the proactive recruitment model? II Successful recruitments are a key to innovative to assess candidates' intrinsic motivation, innovative capabilities and fit to the existing group, a longer follow up and cooperation is needed. Cooperation will give real life evidence of the outcomes even to recruiters who are not coopseration with good groups is crucial; it also enhances the motivation and ambition of one's existing group. The basic model can be systematically used for development in various research settings, but it requires
long term commitment and hard work. 